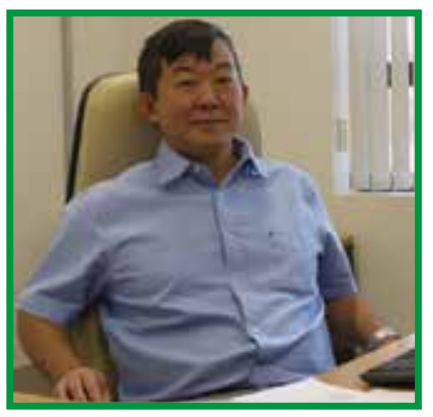

\title{
BrJAC: Eight Years Contributing to Analytical Chemistry
}

\author{
Lauro Tatsuo Kubota \\ Full Professor \\ Institute of Chemistry, University of Campinas - Unicamp \\ Campinas, SP, Brazil \\ kubota@unicamp.br
}

When Brazilian Journal of Analytical Chemistry (BrJAC) was launched in 2010 to document some information that build the history of Analytical Chemistry from the novel discoveries to applications, which contributes to the great improvement in our life quality, it was a big challenge to be undertaken. During these eight years, BrJAC has struggled to grow continuously and keeping the goals that were stablished at beginning, as a dream. Certainly, several improvements have been implemented in order to be better accepted by the people in the academia and industry. It was a privilege to be at the forefront of this project during these years as Editor-in-Chief, but now is time to go, leaving the responsibilities to other people to bring new energies and perspectives to the journal. I have to acknowledge all the people that were involved in this project with me during this time as well as all those who contributed to BrJAC. I am sure that Prof. Marco Aurelio Zezzi Arruda will do an excellent job for the BrJAC. It is important to stress that the success of BrJAC depends on the people who believe in this project and think it is important to the history of Analytical Chemistry. The reason for publishing interviews with renowned people is due to the importance to record the opinion and life history of the well succeeded and recognized people in Analytical Chemistry, showing their contributions to the area. In addition, the sections of point of view and letter are intended to record the opinion of the people about some subjects of Analytical Chemistry that provoke discussions. The articles about researches from the academia and companies are similar to those of any journal. Interesting themes are addressed in the journal, such as forensic science in this issue. I believe that BrJAC will continue to pursue the goals that were originally intended and planned, leaving a legacy for future generations. I hope you can enjoy reading this issue and many others, learning something from the history of Analytical Chemistry. 